\title{
Compliance of a cobalt chromium coronary stent alloy - the COVIS
} trial

\author{
Jens Hagemeister*, Frank M Baer, Robert HG Schwinger and Hans W Höpp
}

Address: Department of Medicine III, University of Cologne, Kerpener Str. 62, 50924 Cologne, Germany

Email: Jens Hagemeister* - jens.hagemeister@uk-koeln.de; Frank M Baer - Frank.Baer@uni-koeln.de;

Robert HG Schwinger - Robert.Schwinger@medizin.uni-koeln.de; Hans W Höpp - hw.hoepp@uni-koeln.de

* Corresponding author

Published: 28 October 2005

Current Controlled Trials in Cardiovascular Medicine 2005, 6:17 doi:10.1 186/1468-6708-6-17

This article is available from: http://cvm.controlled-trials.com/content/6/1/17

(c) 2005 Hagemeister et al; licensee BioMed Central Ltd.

This is an Open Access article distributed under the terms of the Creative Commons Attribution License (http://creativecommons.org/licenses/by/2.0), which permits unrestricted use, distribution, and reproduction in any medium, provided the original work is properly cited.
Received: 18 August 2005

Accepted: 28 October 2005

\begin{abstract}
Background: Cobalt chromium coronary stents are increasingly being used in percutaneous coronary interventions. There are, however, no reliable data about the characteristics of unfolding and visibility of this stent alloy in vivo. The aim of this study is to compare cobalt chromium coronary stents with conventional stainless steel stents using intracoronary ultrasound.
\end{abstract}

Methods: Twenty de novo native coronary stenoses $\leq 20 \mathrm{~mm}$ in length (target vessel reference diameter $\geq 2.5$ and $\leq 4.0 \mathrm{~mm}$ ) received under sequential intracoronary ultrasound either a cobalt chromium stent (Multi-Link Vision ${ }^{\circledR} ; n=10$ ) or a stainless steel stent (Multi-Link Zeta ${ }^{\circledR} ; n=10$ ).

Results: For optimal unfolding, the cobalt chromium stent requires a higher balloon deployment pressure $(13.90 \pm 2.03 \mathrm{~atm})$ than the stainless steel stent $(I 1.50 \pm 2.12 \mathrm{~atm})$. Furthermore, the achieved target vessel diameter of the cobalt chromium stent (Visibility-Index QCA/IVUS MultiLink Vision ${ }^{\circledR}$ I.I3 / Multi-Link Zeta ${ }^{\circledR}$ I.04) is more easily overrated by Quantitative Coronary Analysis.

Conclusion: These data indicate that stent material-specific recommendations for optimal implantation pressure and different stent material with an equal design should both be considered in interpreting QCA-analysis.

\section{Background}

With the addition of coronary stents to percutaneous coronary intervention (PCI), the incidence of re-stenosis has been significantly reduced. Unfortunately, re-stenosis rates still range from $16 \%$ to $32 \%[1]$. Efforts to reduce restenosis include coating of conventional stents and use of alternative materials and design. Drug Eluting Stents (DES) are already established in clinical practice[2], whereas little data are available with respect to innovative stent material.
Cobalt chromium represents a more biocompatible material that is being increasingly used in coronary stents (Guidant Multi-Link Vision ${ }^{\circledast} /$ Guidant Corporation, Driver-Stent $t^{\circledast} /$ Medtronic, Costar-Stent ${ }^{\circledast} /$ Biotronic). In comparison with stainless steel, cobalt chromium has a higher radial strength and radiopacity for similar electronegativity. This allows for the production of thinner struts with a similar radiological visibility[3].

Although, results of two cobalt chromium registries[3,4] are already published, there are no data describing the 
Table I: Baseline Lesion Characteristics (QCA).

\begin{tabular}{lcc}
\hline & ML Vision (n= I0) & ML Zeta (n= I0) \\
\hline Preprocedure reference vessel diameter (mm) & $3.04 \pm 0.34$ & $2.99 \pm 0.47$ \\
Preprocedure MLD (mm) & $0.77 \pm 0.32$ & $0.63 \pm 0.32$ \\
Preprocedure diameter stenosis (\%) & $73.50 \pm 10.30$ & $79.60 \pm 8.80$ \\
Target vessel & & $50 \%$ \\
$\quad$ Left anterior descending & $20 \%$ & $20 \%$ \\
$\quad$ Circumflex & $60 \%$ & $30 \%$ \\
$\quad$ Right coronary artery & $3.34 \pm 0.34$ & $3.31 \pm 0.48$ \\
Postprocedure MLD (mm) & $6.00 \pm 1.80$ & $5.10 \pm 3.80$ \\
Postprocedure diameter stenosis (\%) & & \\
\hline
\end{tabular}

basic characteristics of unfolding of a cobalt chromium stent. This information would be important to know in developing clinical recommendations for different alloys, since optimal inflation and complete adherence to vessel wall are key factors affecting the incidence of re-stenosis.

We investigated the balloon deployment pressure-related behaviour of a cobalt chromium stent (Multi-Link Vision $^{\circledast}$ ), comparing it to a similarly designed conventional stainless steel stent (Multi-Link Zeta ${ }^{\circledR}$ ) using intravascular ultrasound. We also evaluated radiological visibility of both stents and the influence of radiological visibility on QCA-analysis.

\section{Methods}

Eighteen consecutive patients (14 men, 4 women, mean age $61 \pm 9$ years) with twenty single, de novo native coronary stenoses $\leq 20 \mathrm{~mm}$ in length were blindly randomised to either a Multi-Link Vision ${ }^{\oplus}$ cobalt chromium stent $(\mathrm{n}=$ $10)$ or to a Multi-Link Zeta ${ }^{\otimes}$ stainless steel stent $(n=10)$. Additional criteria for inclusion were age $\geq 18$ years, clinical angina and/or a positive functional study and a target vessel reference diameter $\geq 2.5 \mathrm{~mm}$ and $\leq 4 \mathrm{~mm}$.

Patients were excluded from the study if they presented with cardiogenic shock, acute coronary syndrome, intracoronary thrombus, vessel occlusion, target lesions in the left main artery, ostial or bifurcational stenosis, calcification of $\geq 180^{\circ}$ of vessel circumference by intravascular ultrasound (IVUS), diabetes and/or known hypersensitivity to aspirin and clopidogrel. The study was approved by the ethics committee of the University of Cologne and all patients signed written informed consent before participating.

Percutaneous coronary intervention was performed in accordance with standard clinical procedures, and stent implantation without predilatation ("primary stenting") was encouraged. Pretreatment included an oral clopidogrel loading dose of $300 \mathrm{mg}$ and aspirin $500 \mathrm{mg}$ the day before intervention. Peri-interventional, weight-adapted heparin was given intravenously with consecutive control of activated clotting time. Implantation was performed with a primary balloon deployment pressure of 10 atmospheres (atm). If IVUS target criteria were not reached, a standardised further inflation with 13 atm and possibly $16 \mathrm{~atm}$ including additional IVUS control, followed. Postprocedural an oral antiplatelet therapy with clopidogrel $75 \mathrm{mg} /$ day for at least 4 weeks and aspirin $100 \mathrm{mg} /$ day as standard medication was obligatory.

Intravascular ultrasound imaging was performed after administering $0.2 \mathrm{mg}$ of intracoronary nitroglycerin using a $30 \mathrm{MHz}$ transducer within a 3.2 Fr imaging sheath (SCIMED/BSC, Maple Grove, Minnesota) and automatic transducer pullback of $0.5 \mathrm{~mm} / \mathrm{s}$. The distal and proximal reference segment was within $3-5 \mathrm{~mm}$ of the lesion or stent without a relevant stenosis $(<20 \%)$. Quantitative Coronary Analysis (QCA, Pie Medical Imaging) was done for proximal and distal reference diameter (RD), minimal lumen diameter (MLD), diameter of stenosis and acute lumen gain.

The primary endpoint was balloon deployment pressure once IVUS criteria were reached. IVUS target criteria were similar to preceding studies[5], with a minimal lumen area (MLA) after stenting $>90 \%$ (for reference lumen area (RLA) $\leq 9.0 \mathrm{~mm}^{2}$ ), $>80 \%$ (for RLA $>9.0 \mathrm{~mm}^{2}$ ), a MLA > $90 \%$ of proximal RLA at the proximal end of the stent and a complete adherence to vessel wall. A secondary endpoint was angiographic visibility as generated by minimal lumen diameter in QCA and IVUS-analysis, respectively.

Statistical analysis was performed with SPSS, version 12.0 (SPSS Inc., 2003). Continuous variables are expressed as mean $\pm \mathrm{SD}$.

\section{Results}

Clinical data were comparable for both groups, except for the number of smokers (Vision ${ }^{\circledast} n=7$ / Zeta ${ }^{\circledast} n=3$ ), and 


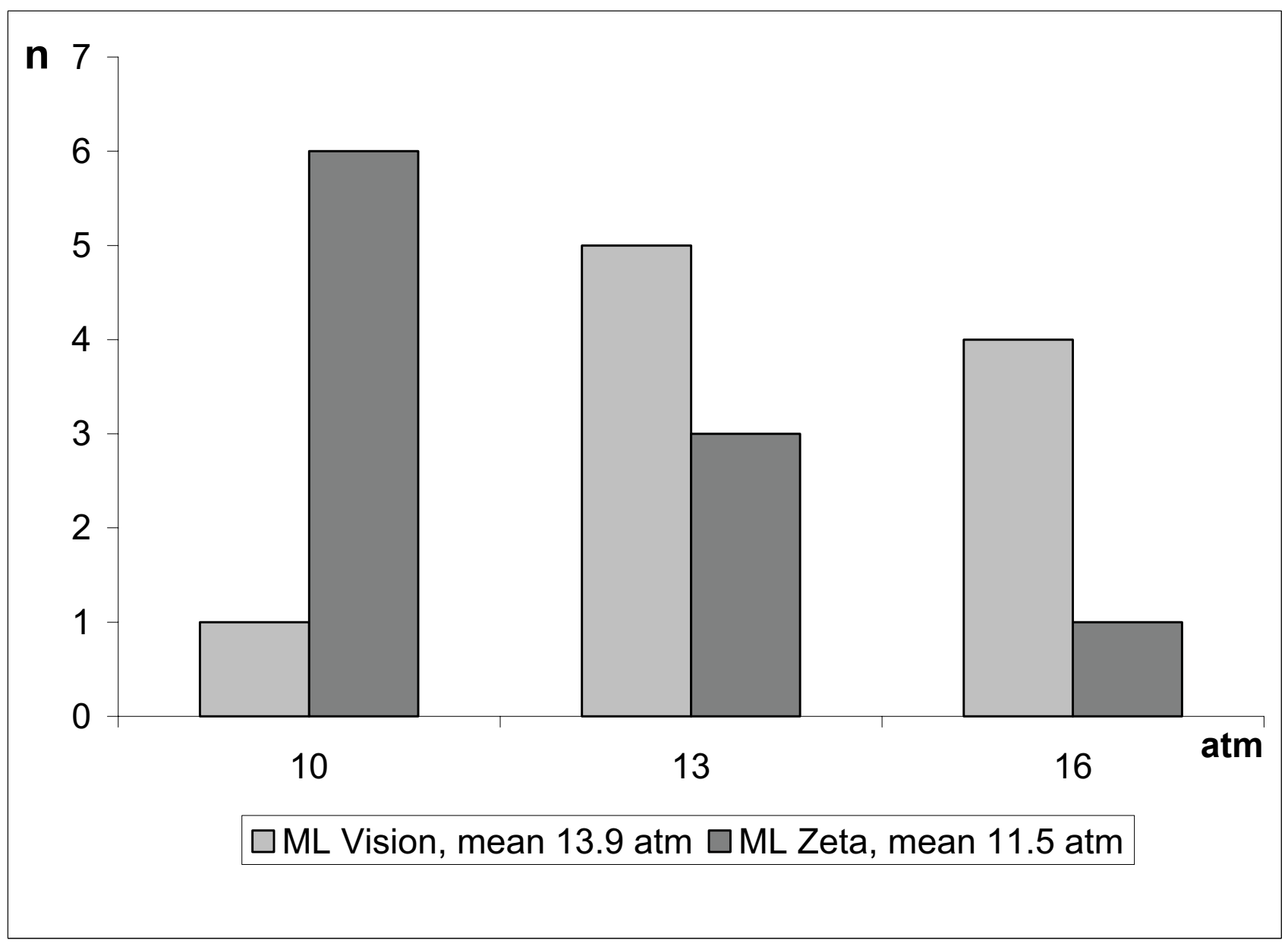

Figure I

Ballon pressure by IVUS-criteria: balloon deployment pressure when IVUS criteria were reached for Multi-Link Vision ${ }^{\circledR}$ and Multi-Link Zeta ${ }^{\circledR}(n=$ number of lesions).

were comparable to prior stent studies. Twenty five stents (13 ML Vision ${ }^{\circledast}, 12$ ML Zeta $^{\circledast}$ ) were implanted with a $100 \%$ procedural success. An intraprocedural dissection in 3 patients required implantation of additional stents. In case of stent overlap, the same stent type was used.

The angiographic mean reference vessel diameter was 3.02 $\pm 0.40 \mathrm{~mm}\left(\right.$ ML Vision ${ }^{\circledR} 3.04 \pm 0.34 \mathrm{~mm} /$ ML Zeta $^{\circledR} 2.99 \pm$ $0.47 \mathrm{~mm}$ ). Mean minimum lumen diameter was $0.70 \pm$ $0.32 \mathrm{~mm}$, which corresponds to a mean diameter stenosis of $76.5 \pm 9.8 \%$ (Table 1$)$.

Pre-dilatation was necessary in one case, in which a $1.5 \times$ $20 \mathrm{~mm}$ balloon was used and dilatation pressure was 8 atm.
Mean balloon deployment pressure when IVUS criteria were reached was $13.90 \pm 2.03$ atm for Multi-Link Vision ${ }^{\circledast}$ and $11.50 \pm 2.12$ atm for Multi-Link Zeta $^{\circledR}$ (Figure 1).

A mean post-procedural QCA-MLD of $3.32 \pm 0.41 \mathrm{~mm}$ and a mean MLD of $3.07 \pm 0.41 \mathrm{~mm}$ by intravascular ultrasound generated a mean Visibility-Index of 1.08. For Multi-Link Vision ${ }^{\circledR}(3.34 \pm 0.34 \mathrm{~mm}$ [QCA] vs. $2.95 \pm 0.17$ mm [IVUS]), mean Visibility-Index was 1.13 . The mean Visibility-Index for Multi-Link Zeta ${ }^{\circledast}(3.31 \pm 0.48 \mathrm{~mm}$ [QCA] vs. $3.19 \pm 0.55 \mathrm{~mm}$ [IVUS]) was 1.04 (Table 2).

\section{Conclusion}

Different material properties of alloys used in a specific stent design represent a key consideration in clinical prac- 
Table 2: Visibility-Index: generated from QCA- and IVUS-data.

\begin{tabular}{lccc}
\hline & All & ML Vision & ML Zeta \\
\hline Postprocedure MLD QCA (mm) & $3.32 \pm 0.41$ & $3.34 \pm 0.34$ & $3.31 \pm 0.48$ \\
Postprocedure MLD IVUS (mm) & $3.07 \pm 0.41$ & $2.95 \pm 0.17$ & $3.19 \pm 0.55$ \\
Visibility [QCA/IVUS] & 1.08 & 1.13 & 1.04 \\
\hline
\end{tabular}

tice that should be taken into account, particularly with regard to balloon deployment pressure. Furthermore, the achieved post-procedure lumen diameter as measured by QCA is more easily overestimated for the cobalt chromium stent than for the stainless steel stent due to material properties.

Based on these results, further investigation of materialspecific changes in stent unfolding is necessary to guide and optimize the clinical implantation practice.

\section{Limitations}

The number of twenty de novo native coronary stenoses is small, but relevant preliminary differences were found that should be further explored in future investigations.

Three standardised balloon deployment pressures (10, 13, 16 atm) were chosen because every change between balloon and IVUS-catheter increases the risk of vascular damage. Thus, a continuous, incremental escalation of balloon deployment pressure is not practical in vivo.

\section{Acknowledgements}

This study was supported by a grant from Guidant Corporation (Indianapolis, IN, USA).

\section{References}

I. Kastrati A, Hall D, Schömig A: Long-term outcome after coronary stenting. Curr Control Trials Cardiovasc Med 2000, I:48-54.

2. Babapulle MN, Joseph L, Belisle P, Brophy JM, Eisenberg MJ: A hierarchical Bayesian meta-analysis of randomised clinical trials of drug-eluting stents. Lancet 2004, 364:558-9.

3. Kereiakes DJ, Cox DA, Hermiller JB, Midei MG, Bachinsky WB, Nukta ED, Leon MB, Fink S, Marin L, Lansky AJ, Guidant Multi-Link Vision Stent Registry Investigators: Usefulness of a cobalt chromium coronary stent alloy. Am J Cardiol 2003, 92:463-6.

4. Sketch MH Jr, Ball M, Rutherford B, Popma JJ, Russell C, Kereiakes DJ, on behalf of the Driver Investigators: Evaluation of the Medtronic (Driver) cobalt-chromium alloy coronary stent system. Am J Cardiol 2005, 95:8-12.

5. Mudra H, di Mario C, de Jaegere P, Figulla HR, Macaya C, Zahn R, Wennerblom B, Rutsch W, Voudris V, Regar E, Henneke KH, Schachinger V, Zeiher A, OPTICUS (OPTimization with ICUS to reduce stent restenosis) Study Investigators: Randomized comparison of coronary stent implantation under ultrasound or angiographic guidance to reduce stent restenosis (OPTICUS Study). Circulation 200I, 104:1343-9.

\section{Publish with Biomed Central and every scientist can read your work free of charge}

"BioMed Central will be the most significant development for disseminating the results of biomedical research in our lifetime. "

Sir Paul Nurse, Cancer Research UK

Your research papers will be:

- available free of charge to the entire biomedical community

- peer reviewed and published immediately upon acceptance

- cited in PubMed and archived on PubMed Central

- yours - you keep the copyright

Submit your manuscript here:

http://www.biomedcentral.com/info/publishing_adv.asp 